\title{
Evaluation of Value Addition on Tomato Training Programme Conducted by the Krishi Vigyan Kendras (Farm Science Centers) in Cuddalore District of Tamil Nadu, India
}

\author{
M. Balarubini, S. Kannan* and Venkatalakshmi
}

KVK, Virudhachalam, India

*Corresponding author

\begin{tabular}{|l|}
\hline Ke y w o r d s \\
$\begin{array}{l}\text { Krishi Vigyan } \\
\text { Kendra, Value } \\
\text { addition, Training, } \\
\text { Content and } \\
\text { Evaluation }\end{array}$ \\
\hline Article Info \\
\hline $\begin{array}{l}\text { Accepted: } \\
\text { 26 December } 2018 \\
\text { Available Online: } \\
\text { 10 January } 2019\end{array}$ \\
\hline
\end{tabular}

A B S T R A C T

Krishi Vigyan Kendras or Farm Science Centres have been established by the Indian Council of Agricultural Research in all districts of Tamil Nadu. The trust areas of KVKs are refinement and demonstration of technologies, and training of farmers, farm women, rural youth and extension functionaries. Imparting trainings in agriculture and allied fields for the rural youth is one of its mandates. Effective training is considered as an important factor in determining the efficiency of an organization which depends upon the capability of its trainees. For training evaluation to be truly effective, the training and development itself must be appropriate for the person and the situation. Even though evaluation is listed at the last phase, evaluation actually happens during all the phases. It is used during the training process to evaluate the training process itself. Value addition in agriculture predominantly offers a means to increase, rejuvenate and stabilize farm income. The results exemplified the effectiveness of tomato value addition training in terms of content of the training programme, time allotted for the course, quality of the material provided, instructors knowledge about the subject, illustration by practical examples, mode of presentation, communication skills, and interaction of the trainer with the trainee. Moreover, the findings of the study conclude education level, innovativeness and attitude towards value addition are contributing factors for improving the positive impact of training.

\section{Introduction}

India faces the most challenging task of transferring the fast emerging agricultural technologies to sustain the increase in farm productivity and economic viability of farming. A variety of extension programmes are implemented for creating awareness, educating and motivating the Agripreneur, farmwomen and youth to adopt and manage the new agricultural technology in the fields and homes. The Indian Council of Agricultural Research (ICAR) institutes, State Agricultural Universities (SAUs) extension system and line departments are involved in transfer of technology. The department of Agriculture and Cooperation under the Union Ministry of Agriculture and the state departments of Agriculture are primarily responsible for the transfer of technology to the farmers, farm women and rural youth. National agricultural extension systems 
worldwide, including India, have undergone major changes during the past two or more decades (Swanson, 2008). In 1998, the government extension system of the Union Ministry of Agriculture and the Provincial Departments of Agriculture switched to Agricultural Technology Management Agency (ATMA), a decentralized model of extension as a part of the World Bank-financed National Agricultural Technology Project (NATP) (Singh et al., 2006). The ICAR is responsible for agriculture research and education through its institutions and 45 state agricultural universities (SAUs), one central agricultural university and four deemed universities. It also operates an extension system by itself called "first line extension system". The ICAR in 1973 appointed a Committee under the Chairmanship of Dr Mohan Singh Mehta for formulating the institutional design of KVKs for providing training in agriculture and allied vocations for the rural youth with emphasis on 'learning by doing' for generating self employment. The first KVK was established in 1974 at Pondicherry under the administrative control of the Tamil Nadu Agricultural University, Coimbatore. Totally $695 \mathrm{KVKs}$ were set up at district headquarters all over India for providing different services to the Agripreneur, farm women and youth. In Tamil Nadu 14 KVKs have been established so far under the control of the Tamil Nadu Agricultural University (TNAU), Coimbatore, India. In this paper we have made an attempt to evaluate the benefits of training programmes to the farm women of Cuddalore.

Training can be stated as the methods which are imparted to the trainee in fulfilling the Krishi Vigyan Kendras goals. Krishi Vigyan Kendras invest huge amounts for training. Krishi Vigyan Kendras involving in the evaluation of training effectiveness are not only responsible for what the trainees learn but they need to see that the knowledge which the trainee gained is being applicable in their work performance. Training and its regular evaluation would definitely make a Centre to stand in the attention in achieving the objectives.

Kirkpatrick (1996) who writes, "Reaction may best be considered as how well the trainees liked a particular training program". This involves in testing the trainees capabilities to perform learned skills while on the field. Primary purpose of training is to improve results by having the trainees learn new skills and knowledge and then actually applying them to the field. It suggested that analysis and evaluation of the trainings organised by the KVKs should be conducted to identify the constraints and impacts (Anonymous, 2002). Agricultural education and research systems in India have not paid due attention to programme evaluation. This study, therefore, seeks to evaluate the outcome and effectiveness of tomato value addition training programmes conducted by the KVKs in terms of content of the training programme, time allotted for the course, quality of the material provided, instructors knowledge about the subject, illustration by practical examples, mode of presentation, communication skills, and interaction of the trainer with the trainee.

\section{Materials and Methods}

Evaluation research is the form of applied social science. Field of evaluation research is the application of scientific methods to measure the implementation and impacts of a programme for decision-making purpose (Rutman, 1984). The purpose of evaluation helps in identifying the key evaluation questions, on the basis of which appropriate form of evaluation, appropriate model of evaluation and design of research can be selected (Peshin et al., 2009). Commonly, two main types of evaluation, based on the purpose of evaluation, are formative and summative valuation (Scriven, 1967). Formative 
evaluation reports to the programme by identifying shortcomings and their remedies, whereas summative evaluation reports about the outcomes/impacts of the programme (Scriven, 1991). The effectiveness of such initiatives has increasingly attracted attention of academics, researchers, planners and decision makers. The interview schedule was developed based on the extensive review of the value addition training contents of KVK (Table 1). The face-to-face interviews were conducted by using a structured questionnaire. The desired outcome or result that will improve the performance of the trainee. The level of performance the learners must be able to do to create the impact. The knowledge and skills they need to learn in order to perform. The Krishi vigyan Kendra assesses its training methods and develops a stout and effective practice. The survey was conducted on a sample of 60 farm women attended the value addition training programme. This has filled by the trainees after the completion of value addition course of tomato during the training program.

\section{Results and Discussion}

It measures the effectiveness of the training program. Evaluation is an essential part of any training programme and it helping to ensure the objectives are met, used to identify the problems and weakness so they can be rectified, it provide information to aid further development.

The general details of the samples for conducting evaluation are given in Table 2. It is evident from the data that only farm women attend the value addition on tomato training programmes. The ability of an individual to perform certain tasks is generally associated with their chronological age and experience in performing a particular task. This is considered as one of the variables in this study and the data collected is presented in Table 2, it is evident that nearly $(79.41 \%)$ of the trainees was middle age group and the remaining came under old $(17.65 \%)$ and young age $(2.94 \%)$ categories. The educational status of the respondents revealed that a majority of them came under Middle school $(70.59 \%)$ and followed by secondary level $(17.65 \%)$, primary level $(8.82 \%)$ and college level $(2.94 \%)$.

It could be observed that 72.06 per cent of the respondents had farming and business as their occupation and of the respondents 22.06 per cent had farming and Agril. labour. The rest (5.88\%) had farming and service as their subsidiary occupation. It could be seen from the Table 2 that a majority $(52.94 \%)$ of the respondents were found to be distributed in medium income upto Rs. 40,000/-. The respondents had low level $(41.18 \%)$ of annual income and 5.88 per cent of the respondents had annual income was high of above Rs. 40,000/-.

An analysis of the training undergone revealed that 79.41 per cent of the respondents belonged to high category and remaining belonged to medium category $(20.59 \%)$ and no one is under low category. The reason might be due to the availability of Krishi Vigyan Kendra training centers and the high level of exposure and interest among the farm women. The quality of being novel and the originality of introducing new ideas is known as innovativeness. The distribution of farm women according to their level of innovativeness reveal that 69.12 per cent of the respondents had medium level of innovativeness followed by high (22.06 \%) and low $(8.82 \%)$ level of innovativeness.

The reactions with respect to the trainers, subject matter, physical facilities and teaching materials were studied. A majority of the trainees, 57.14 per cent in value addition considered the training content of the course is 
Excellent (Table 3). Majority of trainees (75.00 \% for value addition) were satisfied with the quality of the material provided is excellent and 60.71 per cent of the respondents in value addition expressed that the practical examples was excellent. Majority of trainees $(57.14 \%$ for value addition) were satisfied with the presentation methods is good.

Table.1 Sampling plan for the study

\begin{tabular}{|c|l|c|}
\hline \multicolumn{1}{|c|}{ Name of course } & Name of KVK & Number of trained farm women \\
\hline Value addition of Tomato & $\begin{array}{l}\text { Krishi Vigyan Kendra, } \\
\text { Vridhachalam }\end{array}$ & 68 \\
\hline
\end{tabular}

Table.2 Distribution of respondents according to the Profile ( $\mathrm{n}=68)$

\begin{tabular}{|c|c|c|c|c|}
\hline S. No. & Name of the variable & Category & Number & Per cent \\
\hline \multirow[t]{4}{*}{1} & \multirow[t]{4}{*}{ Age } & Young & 2 & 2.94 \\
\hline & & Middle aged & 54 & 79.41 \\
\hline & & Old & 12 & 17.65 \\
\hline & & Total & 68 & 100.00 \\
\hline \multirow[t]{6}{*}{2} & \multirow[t]{6}{*}{ Education } & Illiterate & 0 & 0.00 \\
\hline & & Primary level & 6 & 8.82 \\
\hline & & Middle level & 48 & 70.59 \\
\hline & & Secondary level & 12 & 17.65 \\
\hline & & Collegiate level & 2 & 2.94 \\
\hline & & Total & 68 & 100.00 \\
\hline \multirow[t]{5}{*}{3} & \multirow{5}{*}{ Trainee occupation } & Farming as Sole occupation & 0 & 0.00 \\
\hline & & Farming + Agrl.labour & 15 & 22.06 \\
\hline & & Farming + Business & 49 & 72.06 \\
\hline & & Farming + Service & 4 & 5.88 \\
\hline & & Total & 68 & 100.00 \\
\hline \multirow[t]{4}{*}{4} & \multirow[t]{4}{*}{ Annual income } & Low(Below 20,000) & 28 & 41.18 \\
\hline & & $\begin{array}{l}\text { Medium(Above 20,000-upto } \\
40,000 \text { ) }\end{array}$ & 36 & 52.94 \\
\hline & & High(Above 40,000) & 4 & 5.88 \\
\hline & & Total & 68 & 100.00 \\
\hline \multirow[t]{4}{*}{5} & \multirow[t]{4}{*}{ Trainings Undergone } & Low (4-5 Scores) & 0 & 0.00 \\
\hline & & Medium (6-7 Scores) & 14 & 20.59 \\
\hline & & High (8-10 Scores) & 54 & 79.41 \\
\hline & & Total & 68 & 100.00 \\
\hline \multirow[t]{4}{*}{6} & \multirow[t]{4}{*}{ Innovativeness } & Low & 6 & 8.82 \\
\hline & & Medium & 47 & 69.12 \\
\hline & & High & 15 & 22.06 \\
\hline & & Total & 68 & 100.00 \\
\hline
\end{tabular}


Table.3 Effectiveness of the trainees

\begin{tabular}{|c|c|c|c|c|c|c|c|}
\hline S.No & \multicolumn{2}{|l|}{ Contents } & Excellent & Very & Good & Poor & Very \\
\hline \multirow[t]{2}{*}{1.} & \multirow[t]{2}{*}{ Content of the course } & Frequency & 32 & 24 & 0 & 0 & 0 \\
\hline & & Percentage & 57.14 & 42.86 & 0.00 & 0.00 & 0.00 \\
\hline \multirow[t]{2}{*}{2.} & \multirow[t]{2}{*}{ Time allotted for the course } & Frequency & 22 & 26 & 8 & 0 & 0 \\
\hline & & Percentage & 39.29 & 46.43 & 14.29 & 0.00 & 0.00 \\
\hline \multirow[t]{2}{*}{3.} & \multirow[t]{2}{*}{ Quality of the material provided } & Frequency & 42 & 14 & 0 & 0 & 0 \\
\hline & & Percentage & 75.00 & 25.00 & 0.00 & 0.00 & 0.00 \\
\hline \multirow[t]{2}{*}{4.} & \multirow{2}{*}{$\begin{array}{l}\text { Instructors knowledge about the } \\
\text { subject }\end{array}$} & Frequency & 35 & 21 & 0 & 0 & 0 \\
\hline & & Percentage & 62.5 & 37.5 & $\mathbf{0}$ & 0 & $\mathbf{0}$ \\
\hline \multirow[t]{2}{*}{5.} & \multirow[t]{2}{*}{ Illustration by practical examples } & Frequency & 34 & 22 & 0 & 0 & 0 \\
\hline & & Percentage & 60.71 & 39.29 & 0.00 & 0.00 & 0.00 \\
\hline \multirow[t]{2}{*}{6.} & \multirow[t]{2}{*}{ Presentation methods } & Frequency & 5 & 19 & 32 & 0 & 0 \\
\hline & & Percentage & 8.93 & 33.93 & 57.14 & 0.00 & 0.00 \\
\hline \multirow[t]{2}{*}{7.} & \multirow[t]{2}{*}{ Communication skills } & Frequency & 18 & 14 & 24 & 0 & 0 \\
\hline & & Percentage & 32.14 & 25.00 & 42.86 & 0.00 & 0.00 \\
\hline \multirow[t]{2}{*}{8.} & \multirow[t]{2}{*}{ Questions handling } & Frequency & 7 & 9 & 23 & 17 & 0 \\
\hline & & Percentage & 12.50 & 16.07 & 41.07 & 30.36 & 0.00 \\
\hline \multirow[t]{2}{*}{9.} & \multirow{2}{*}{$\begin{array}{l}\text { Interaction of the trainer with the } \\
\text { trainees }\end{array}$} & Frequency & 13 & 14 & 29 & 0 & 0 \\
\hline & & Percentage & 23.21 & 25.00 & 51.79 & 0.00 & 0.00 \\
\hline
\end{tabular}

\section{Effectiveness of training}

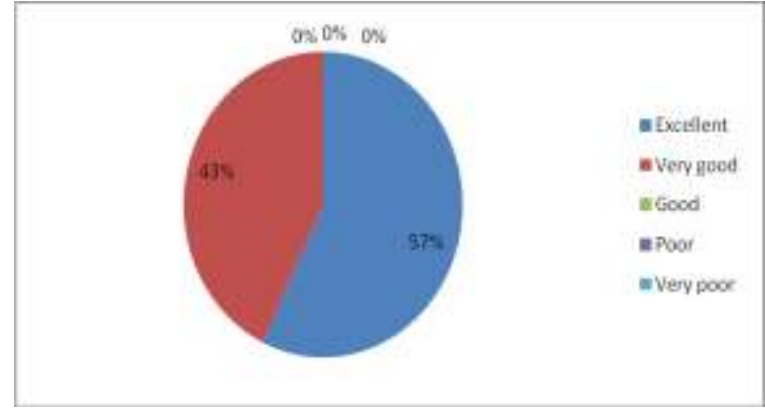

Figure 1: Content of the course

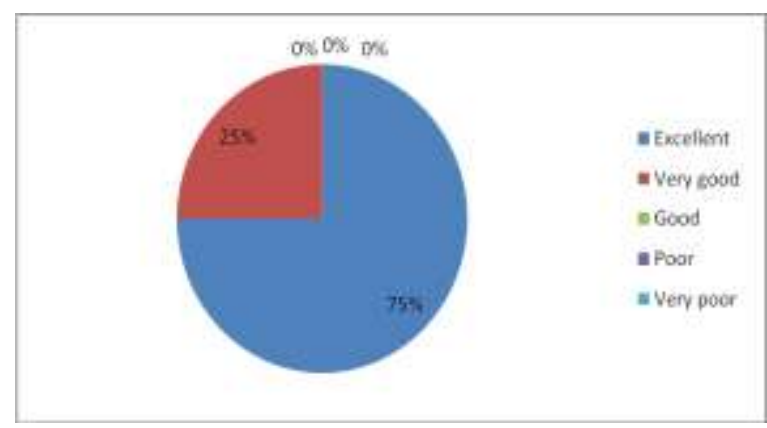

Figure 3: Quality of the material provided

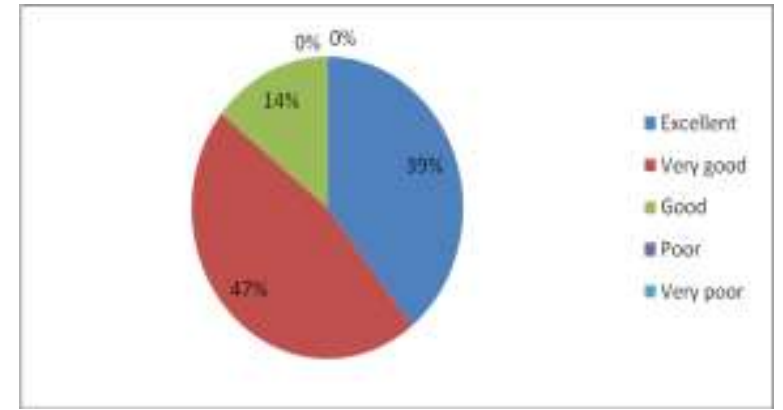

Figure 2: Time allotted for the course

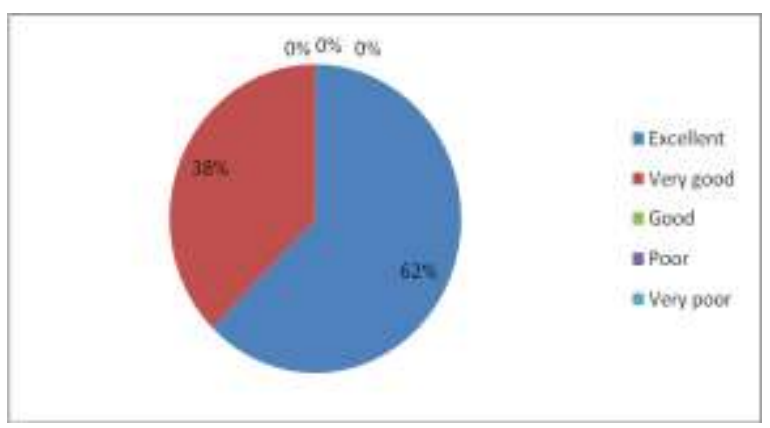

Figure 4: Instructors knowledge about the subject 


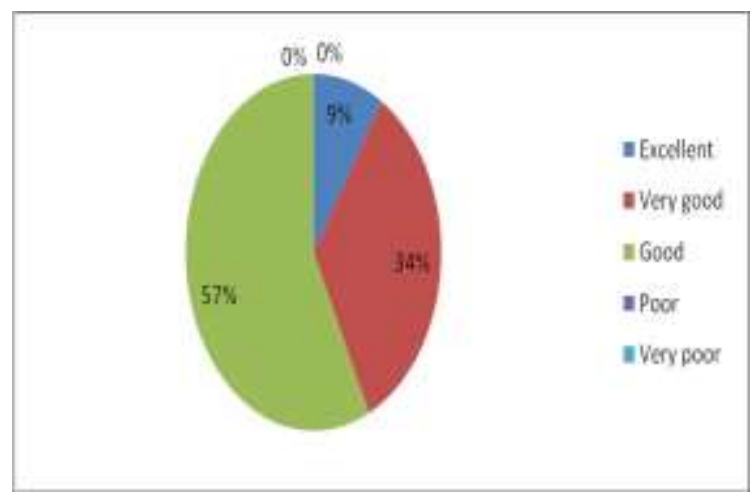

Figure 5: Presentation methods

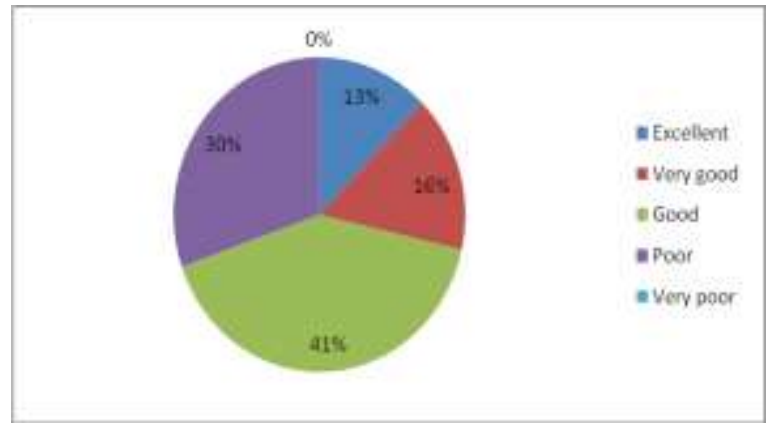

Figure 7: Questions handling

In conclusion the result clearly indicates that the KVKs are realising the objectives of the training programmes in terms of achieving desired outcomes and impacts. The results of the study show that majority of the trainees were satisfied with the training provided by the KVK and has resulted in significant effectiveness of the trainees. Specifically, the study examines the vital issues on what aspect the State Government needs work and invest to be further reinforcing human resource development as a strategy for improving value addition in agriculture. Results from this research study also revealed that training environment is favorable, material provided was excellent, training offered a mix of pedagogical and technological experience to deliver effective solutions and the learning phase is evaluated. Hence, the research showed that the evaluation of training to the

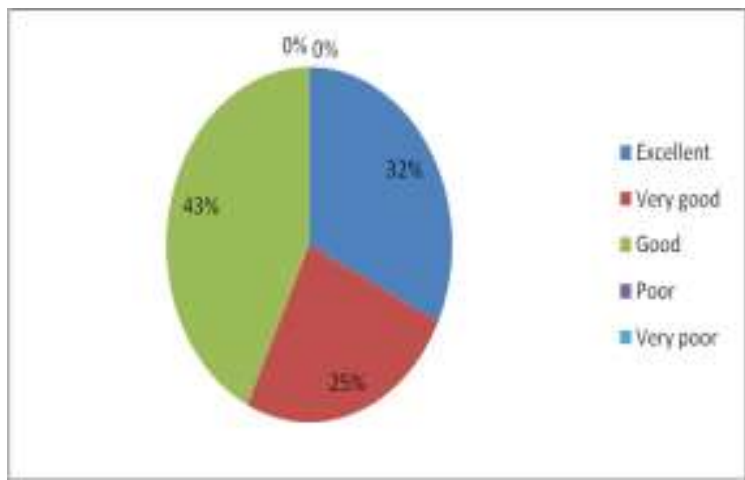

Figure 6: Communication skills

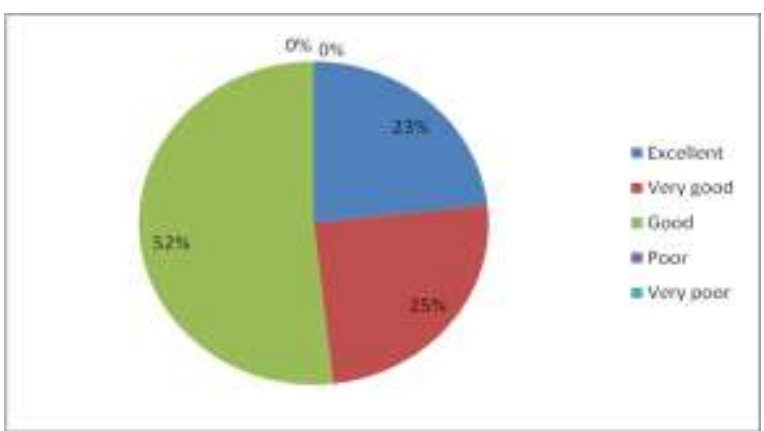

Figure 8: Interaction of the trainer with the trainees

farm women has been positive and valuable sign. The outcome implied that the government effort to improve the farm women performance and potential through the training intervention had been meaningful as this initiative had not only brought positive impact to the farm women themselves but, to a larger extent, had indirectly contributed to the economy of the country.

\section{References}

Anonymous (2002). Report of the Committee on Streamlining the Functioning of Krishi Vigyan Kendras in the Country. Division of Agricultural Extension, Indian Council of Agricultural Research, Krishi Anusandhan Bhawan, Pusa, New Delhi, India.

Kirkpatrick, D. L. (1996). Techniques for 
Evaluating Training programs. Evaluating training programs D. L. Kirkpatrick (ed.) Alexandria, VA: ASTD.

Peshin, R., Jayaratne, J. and Singh, G. (2009). Evaluation research: Methodologies for evaluation of IPM programs. In R. Peshin, and A. K. Dhawan (Eds.), Integrated Pest Management: Dissemination and Impact, Vol.2 (pp. 31-78). Springer Verlag.

Rutman, L. (1984). Evaluation Research Methods. Sage Newbury park, California, USA.

Scriven, M. (1967). The methodology of evaluation. In R. E. Stake (Ed.), Curriculum Evaluation. Rand McNally, Chicago, USA.

Scriven, M. (1991). Evaluation Thesaurus (4th ed). Sage, Newbury Park, California, USA.

Singh, J. P., Swanson, B. E. and Singh, K. M. (2006). Developing a decentralized, market-driven extension system in India: The ATMA model. In A. W. van de Ban, and R. K. Samanta (Eds.), Changing Roles of Agricultural Extension in Asian Nations (pp. 203223). B. R. Publishing, Delhi, India.

Swanson, B. E. (2008). Global Review of Good Agricultural Extension and Advisory Service Practices. FAO, Natural Resources Management and Environment Department, Rome. URL http://www.fao.org/docrep/011/i0261e /i0261e00.html.

\section{How to cite this article:}

Balarubini, M., S. Kannan and Venkatalakshmi. 2019. Evaluation of Value Addition on Tomato Training Programme Conducted by the Krishi Vigyan Kendras (Farm Science Centers) in Cuddalore District of Tamil Nadu, India. Int.J.Curr.Microbiol.App.Sci. 8(01): 3037-3043. doi: https://doi.org/10.20546/ijcmas.2019.801.323 